\title{
Extrusion cooking of a high-fibre cereal product
}

\section{Effects on digestibility and absorption of protein, fat, starch, dietary fibre and phytate in the small intestine}

\author{
BY ANN-SOFIE SANDBERG, HENRIK ANDERSSON, \\ BARBRO KIVISTÖ AND BRITTMARIE SANDSTRÖM \\ Department of Clinical Nutrition, University of Göteborg, Sahlgren's Hospital, \\ S-413 45 Gothenburg, Sweden
}

(Received 17 December 1984 - Accepted 16 October 1985)

\begin{abstract}
1. The effect of extrusion cooking of a high-fibre cereal product on digestibility of starch, fibre components and phytate in the stomach and small intestine was studied by in vivo digestion in ileostomy subjects, as well as its effect on ileostomy losses of fat, nitrogen, sodium and potassium.

2. Seven ileostomy subjects were studied during two periods (each of $4 \mathrm{~d}$ ) while on a constant low-fibre diet supplemented with $54 \mathrm{~g} / \mathrm{d}$ of a bran-gluten-starch mixture (period A) or the corresponding extruded product (period B).

3. Extrusion cooking, using mild conditions, did not change the content of starch, dietary fibre components or phytate of the bran product, but the phytase (EC 3.1.3.26) activity was lost. During the period using the extruded bran product, there was a significant increase in recovery of phytate-phosphorus (period $\mathrm{A}, 44 \%$ of intake; period $\mathrm{B}, 73 \%$ of intake). The amount of fibre components, fat, fatty acids, $\mathrm{N}, \mathrm{Na}, \mathrm{K}$, water and the ash weight of the ileostomy contents did not differ between the two periods. Only 0.6 and $0.7 \%$ respectively of ingested starch was recovered in ileostomy contents in periods $\mathbf{A}$ and $\mathbf{B}$, while the fibre components were almost completely recovered.

4. Extrusion cooking, using even mild conditions, may lead to a considerable impairment in the digestion of phytate, probably due to a qualitative change in phytate and a loss of phytase activity. Starch, before and after extrusion cooking, is almost completely digested in the stomach and small intestine while fibre components are digested to a very small extent.
\end{abstract}

Since extrusion cooking is used increasingly for the production of weaning food, breakfast cereals and bread products, a thorough knowledge of its effect on nutritional value is essential. Very little information is available in the literature on the effects of extrusion cooking on dietary fibre in cereals and other fibre-rich foods (Björck \& Asp, 1983).

Under certain conditions a chemical modification of starch and fibre components can occur (Westerlund \& Theander, 1984). Extrusion cooking of food also leads to the formation of amylose-lipid complexes (Mercier, 1980) which may affect its digestibility. Studies in rats have demonstrated a decrease in protein nutritional value of foods after extrusion cooking (Harper \& Jansen 1981; Linko et al. 1981; Björck et al. 1983).

The significance of these effects on the digestion and absorption of nutrients in man is not known. However, the glucose and insulin responses (Björck, 1984) seem to increase after consumption of extruded bran as compared with unprocessed bran.

Cereals are rich in phytate and fibre components which have a mineral-binding capacity in vitro, suggesting that they might have an inhibitory effect on mineral absorption. Studies in man indicate that the high content of phytate rather than fibre is the main negative factor for mineral absorption (McCance \& Widdowson, 1942 $a$, $b$; Hallberg, 1984; Nävert et al. 1985).

The effect of extrusion cooking of cereals on phytate has not been considered in the I terature. In the present investigation, we aimed to determine whether extrusion cooking of a high-fibre cereal product under mild conditions affects the digestibility of starch, dietary 
fibre components and phytate in the stomach and small intestine of man and if it has any effect on digestion and absorption of fat and protein and excretion of sodium and potassium.

\section{SUBJECTS AND METHODS}

\section{Subjects}

Seven subjects, four men (mean age 50 years, range $39-58$ years) and three women (mean age 31 years, range 23-39 years), volunteered to take part in the study.

All the subjects had previously been proctocolectomized for ulcerative colitis (three subjects) or Crohn's disease of the colon (four subjects), and had well-established ileostomies, with only a minor portion of the terminal ileum $(30-50 \mathrm{~mm})$ removed. The ileostomies functioned properly and the volumes of excreta were within the normal range without the use of drugs. No drugs were taken during the study.

\section{Experimental model}

The study on each subject extended over a period of 2 weeks. During four consecutive days of the first week, starting on Monday at breakfast and ending on Friday morning, the patients were given a constant low-fibre diet with the addition of either $54 \mathrm{~g} / \mathrm{d}$ of a bran-gluten-starch mixture (period A) or the corresponding extruded product (period B) in random order. At the weekend the patients had no dietary restrictions. During the next week, a similar regimen was followed, using the reverse supplement.

\section{Extrusion cooking and conditions.}

The extrusion was performed in a Creusot-Loire BC extruder (Firminy, France) with co-rotating double screw with the following configuration: transport, low pressure, medium-pressure, high-pressure and reverse-screw elements. Noexternal heat was transferred to the barrel or the screws during extrusion. Instead, the barrel was cooled with a specially-designed air-cooling device. Mass temperature and pressure were measured with a Dynisco probe in the compression chamber just before the dies and were determined as $120^{\circ}$ and 5.9 MPa respectively. The screw speed was $150 \mathrm{rev} . / \mathrm{min}$. During extrusion of the mixture, which was composed of $(\mathrm{g} / \mathrm{kg}) 300 \mathrm{bran}, 600$ starch and 100 gluten, water was added at $82 \mathrm{ml} / \mathrm{kg}$.

\section{Diets}

The intake was kept constant on an individually-selected energy level to maintain energy balance; the subjects were weighed at the start and end of each period. The study was preceeded by a test day in which breakfast was composed of white bread, margarine, cheese and milk, coffee or tea and was served in the metabolic ward. The subjects took the lunch, dinner and supper to their homes for consumption. For lunch the subjects could choose either plaice or chicken, both dishes with rice and sauce. The dinner consisted of fillet of pork, rice, sauce and grated cheese and the supper contained white bread, margarine, cheese and a sponge cake. The subjects could choose either tea or coffee for breakfast and supper, and beer, mineral water or milk for lunch and dinner. For each patient the same menu was repeated daily throughout the study.

In period $A$, the ingredients of the product $(32.4 \mathrm{~g}$ wheat starch, $5.4 \mathrm{~g}$ gluten and $16.2 \mathrm{~g}$ wheat bran) were mixed in the boiled rice, half the mixture taken at lunch and the other half at dinner. Gluten and starch were heated with the rice for $5 \mathrm{~min}$ to permit gelatinization of the starch. The bran was added just before serving. In period B, $54 \mathrm{~g}$ of the extruded bran product, which resembled a crispbread, was taken daily, half of it with lunch and the 
other half with dinner. All the food for the subjects was prepared in advance in the metabolic-ward kitchen. The same batches of fish and meat were used for all patients. Meat and fish portions were stored at $-18^{\circ}$ after cooking, then thawed and heated in an oven, either by the subjects themselves, when they had the meals at home, or by the staff in the metabolic-ward kitchen.

No other food consumption was allowed and the subjects were instructed not to leave any food.

Duplicate portions of the diet were collected on days 2 and 4 in each period, homogenized and freeze-dried to constant weight as previously described (Sandberg et al. 1981) and then analysed.

\section{Collection of ileostomy contents}

Ileostomy contents were collected during four consecutive days in each period (from Monday morning to Friday morning). Ileostomy bags were changed every $2 \mathrm{~h}$ during the day, commencing at 07.00 hours and ceasing on retiring at night. The bags were immediately frozen on dry ice in a Dewar vessel which the subjects kept at home. The following day they left their frozen ileostomy bags at the metabolic ward, where the bags were weighed, stored at $-20^{\circ}$ and then freeze-dried to constant weight. The freeze-dried ileostomy contents from each day were pooled and homogenized and portions taken for analysis.

\section{Analytical methods}

Determinations of the wet weight, dry weight, ash weight and nitrogen content of the diets and ileostomy contents were performed as previously described (Sandberg et al. 1981). Neutral polysaccharide constituents of diets, of the extruded bran product and the raw bran, gluten and starch were determined according to the method of Theander \& Westerlund (1986). Freeze-dried samples $(1 \mathrm{~g})$ were extracted with ethanol $(800 \mathrm{ml} / 1 ; 75 \mathrm{ml}, 45 \mathrm{~min})$ and hexane $(50 \mathrm{ml}, 30 \mathrm{~min})$. The extracted residue was dried at $50^{\circ}$ in a water-bath. Starch was digested with a thermo-stable amylase (Termamyl, Novo) in acetate buffer in a boiling water-bath for $30 \mathrm{~min}$ and then with amylo-glucosidase (EC 3.2.1.3) at $60^{\circ}$ for $16 \mathrm{~h}$. Absolute ethanol $(80 \mathrm{ml})$ was added and stirred and the mixture cooled $\left(+4^{\circ}, 30 \mathrm{~min}\right)$, centrifuged and decanted. The precipitate was centrifuged and washed twice with $80 \mathrm{ml}$ ethanol and then with $50 \mathrm{ml}$ acetone. Starch was analysed by spectrophotometric determination of glucose in a portion of the combined supernatant fractions.

The starch-free residue was stirred with acetone, centrifuged and decanted. The residue was air-dried overnight at room temperature. Neutral polysaccharide constituents of the starch-free residue were determined, after sulphuric acid hydrolysis and gas-liquid chromatography of their alditol acetates. $\beta$-D-Allose was used as an internal standard. Klason lignin was determined gravimetrically.

Determination of starch and neutral polysaccharide constituents of ileostomy contents was performed according to the method of Theander \& $\AA$ man (1979) as previously described (Sandberg et al. 1981), except that $\beta$-D-Allose instead of myo-inositol was used as the internal standard.

Phytate in ileostomy contents, diets, the extruded bran product and the raw ingredients was determined as phytate-phosphorus by a modification (Sandberg et al. 1982 b) of the iron-precipitation method of Ellis et al. (1977). Samples of $0.5 \mathrm{~g}$ freeze-dried diet or ileostomy contents were extracted with $20 \mathrm{ml} 0.5 \mathrm{M}$-hydrochloric acid containing sodium sulphate $(50 \mathrm{~g} / 1)$, filtered through a Munktell $\mathrm{OOH}$ filter, frozen overnight and filtered through an MF-Millipore filter $(0 \cdot 10 \mu \mathrm{m}$ pore size) under pressure. Each sample was then precipitated with ferric ions by adding $1 \mathrm{ml}$ ferric chloride $(4 \mathrm{~g} / \mathrm{l})$ in $0.5 \mathrm{M}-\mathrm{HCl}$ containing $\mathrm{Na}_{2} \mathrm{SO}_{4}(50 \mathrm{~g} / \mathrm{l})$ to $50 \mathrm{ml}$ of the filtrate. The mixture was kept in a $95^{\circ}$ water-bath for $20 \mathrm{~min}$, 
cooled and centrifuged at $2300 \mathrm{rev} / \mathrm{min}$ for $20 \mathrm{~min}$ at $20^{\circ}$. The ferric precipitate was washed three times with $5 \mathrm{ml} 0.5 \mathrm{M}-\mathrm{HCl}$ and then dissolved in $1 \mathrm{ml}$ concentrated $\mathrm{H}_{2} \mathrm{SO}_{4}$. From each tube $0.75 \mathrm{ml}$ was withdrawn for wet-ashing at $295^{\circ}$ for $15 \mathrm{~min} ; 0.25 \mathrm{ml}$ hydrogen peroxide $(300 \mathrm{ml} / 1)$ was added, and then the wet-ashing was continued for another $15 \mathrm{~min}$. The digest was quantitatively transferred to a $10 \mathrm{ml}$ flask, diluted with approximately $8 \mathrm{ml}$ demineralized water, kept in a boiling water-bath for $15 \mathrm{~min}$ and then cooled and made up to volume. The flasks were allowed to stand at room temperature overnight and then analysed for $\mathbf{P}$ according to Fiske \& Subbarow (1925). Addition of calcium hydrogen phosphate to samples from the diets and ileostomy contents verified that no co-precipitation of inorganic phosphate occurred, when phytate was precipitated with $\mathrm{Fe}^{3+}$ as described previously.

Phytase (EC 3.1.3.26) activity in the extruded-bran product was determined by analysis of phytate before and after incubation at optimal conditions for phytase, i.e. at $55^{\circ}$ with ten times its weight of water for $17 \mathrm{~h}$ at $\mathrm{pH} 4 \cdot 5$. After incubation, the product was freeze-dried before analysis of phytate.

Total fat and fatty acids were analysed according to Van de Kaamer et al. (1949).

\section{Statistical methods}

For statistical comparison of the results from the two periods, Student's paired $t$-test was used.

\section{Ethical considerations}

The Ethical Committee of Sahlgren Hospital approved the study.

\section{RESULTS}

\section{Diets}

The composition of the diets is summarized in Table 1. The extruded product and its raw ingredients were analysed separately and their composition is given in Table 2 . There was no change after extrusion cooking except in phytase activity as measured indirectly. The raw bran contained $0.321 \mathrm{mmol}$ phytate-P/g before incubation at optimal conditions for phytase and, after incubation, $0.085 \mathrm{mmol}$ phytate- $\mathrm{P} / \mathrm{g}$. The extruded product contained equal amounts before and after incubation.

\section{Ileostomy contents}

The wet weight, dry weight, water, ash, N, fat and electrolyte concentrations of ileostomy contents are summarized in Table 3 . The weight of ileostomy contents varied considerably from individual to individual and was greatest in patient no. 5 , but the day-to-day variation in each period was small.

The excretion of $\mathrm{N}$, fat and fatty acids did not differ between the two periods.

There was no significant difference in excretion of $\mathrm{Na}$ and $\mathrm{K}$ between the two periods. The $\mathrm{Na}$ excretion correlated well with the wet weight of ileostomy contents ( $r 0.99)$.

\section{Polysaccharides and lignin excretion}

Values for the different components of the polysaccharides in the ileostomy contents from periods $A$ and $B$ are given in Table 4. There was no significant difference between periods $A$ and $B$ in the excretion of any of the polysaccharide components.

Starch was almost completely digested in the stomach and small intestine. Only a mean of 0.6 (SE 0.09$) \%$ of the intake in period A and 0.7 (SE 0.12$) \%$ in period B was recovered in ileostomy contents. 
Table 1. Composition $(g / d)$ of low-fibre diet

\begin{tabular}{lccc}
\hline & Mean & SE & Range \\
\hline Energy intake & & & \\
MJ & 9.0 & 0.61 & $6 \cdot 3-10 \cdot 8$ \\
kcal & 2140 & - & - \\
Calculated values* & & & $540-1140$ \\
Water & 896 & 87 & $9 \cdot 1-16 \cdot 4$ \\
Ash & $11 \cdot 9$ & $0 \cdot 9$ & $77-127$ \\
Fat & 102 & $7 \cdot 2$ & $102-186$ \\
Carbohydrates & 152 & $13 \cdot 1$ & \\
Analytical values & & & $79-132$ \\
Protein (nitrogen $\times 6 \cdot 25)$ & 98 & $6 \cdot 7$ & $83-131$ \\
Starch & 107 & $7 \cdot 5$ & $3 \cdot 6-10 \cdot 6$ \\
NSP & $6 \cdot 7$ & 0.98 & $69-171$ \\
Sodium (mmol) & 126 & $14 \cdot 3$ & $29-48$ \\
Potassium (mmol) & $37 \cdot 3$ & $2 \cdot 3$ & $1 \cdot 32-2 \cdot 76$ \\
Phytate-phosphorus (mmol) & $2 \cdot 11$ & $0 \cdot 18$ & \\
\hline
\end{tabular}

NSP, non-starch-polysaccharides.

* Calculated from food tables (Swedish National Food Administration, 1978).

Table 2. Chemical composition of raw ingredients and extruded product $(\mathrm{g} / \mathrm{kg}$ fresh weight $)$

\begin{tabular}{lrccc}
\hline & & & & $\begin{array}{c}\text { Extruded product }(\mathrm{g} / \mathrm{kg}: \\
300 \text { bran, } 600 \text { starch, } \\
100 \text { gluten) }\end{array}$ \\
& Bran & Starch & Gluten & \\
Moisture & 86 & 96 & 51 & 81 \\
Nitrogen & 22 & 0 & 133 & 20 \\
Starch & 92 & 830 & 70 & 530 \\
NSP & 355 & 15 & 25 & 116 \\
Klason lignin & 73 & $1 \cdot 0$ & 18 & 17 \\
Phytate-phosphorus (mmol) & 415 & 0 & $3 \cdot 6$ & 125 \\
\hline
\end{tabular}

NSP, non-starch-polysaccharides.

The mean excretion of Klason lignin during period A and period B was $1 \cdot 2(\mathrm{sE} 0 \cdot 19) \mathrm{g} / 24 \mathrm{~h}$ and $1.5(\mathrm{SE} 0.39) \mathrm{g} / 24 \mathrm{~h}$ respectively. There was no significant change.

\section{Excretion and recovery of phytate}

The mean excretion of phytate-P during period A was 3.87 (SE 0.49 ) $\mathrm{mmol} / 24 \mathrm{~h}$ and, during period B, was 6.39 (SE 0.64$) \mathrm{mmol} / 24 \mathrm{~h}$, i.e. a significant increase when the extruded bran product was consumed $(P<0.001)$.

The recovery of phytate-P as a percentage of intake is shown in Fig 1 . As the intake of phytate was equal in both periods the recovery increased significantly during the period with the extruded product $(P<0.001)$. Between 33 and $72 \%$ (mean $43.9 \%$ ) of phytate-P from the diet was found in ileostomy contents during period $\mathrm{A}$ and between 55 and $104 \%$ (mean 72.9) during period $\mathrm{B}$. 


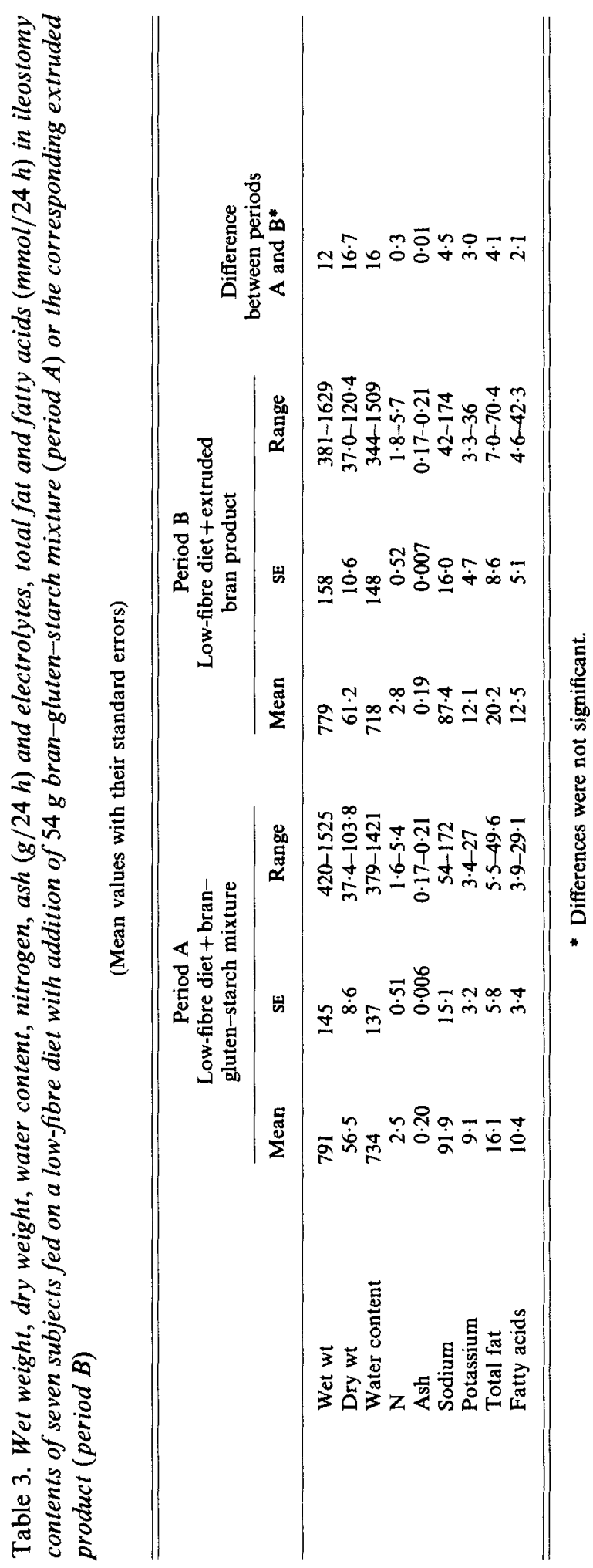


Table 4. Polysaccharides $(\mathrm{g} / 24 \mathrm{~h})$ in ileostomy contents of seven subjects on a low-fibre diet with addition of $54 \mathrm{~g}$ bran-gluten-starch mixture (period $A$ ) or the corresponding extruded product (period $B)$

(Mean values with their standard errors)

\begin{tabular}{|c|c|c|c|c|c|c|c|}
\hline & \multicolumn{3}{|c|}{$\begin{array}{l}\text { Period A } \\
\text { Low-fibre diet + bran- } \\
\text { gluten-starch mixture }\end{array}$} & \multicolumn{3}{|c|}{$\begin{array}{c}\text { Period B } \\
\text { Low-fibre diet }+ \text { extruded } \\
\text { bran product }\end{array}$} & \multirow{2}{*}{$\begin{array}{c}\text { Difference } \\
\text { between periods } \\
\mathbf{A} \text { and } \mathbf{B}^{*}\end{array}$} \\
\hline & Mean & SE & Range & Mean & $\mathrm{SE}$ & Range & \\
\hline Starch & 0.84 & 0.13 & $0.3-1.4$ & 0.98 & $0 \cdot 12$ & $0.5-1.4$ & 0.14 \\
\hline \multicolumn{8}{|l|}{$\begin{array}{l}\text { Neutral } \\
\text { polysaccharide } \\
\text { constituents }{ }^{\dagger}\end{array}$} \\
\hline Rhamnose & Trace & - & 一 & Trace & - & - & - \\
\hline Fucose & 0.46 & 0.06 & $0.21-0.68$ & 0.50 & 0.08 & $0.25-0.88$ & 0.04 \\
\hline Arabinose & $2 \cdot 02$ & $0 \cdot 16$ & $1.45-2 \cdot 60$ & $2 \cdot 12$ & 0.17 & $1 \cdot 55-2 \cdot 54$ & $0 \cdot 10$ \\
\hline Xylose & $3 \cdot 39$ & 0.23 & $3 \cdot 10-4 \cdot 12$ & 3.67 & 0.28 & $3.01-4 \cdot 54$ & 0.28 \\
\hline Mannose & 0.65 & 0.15 & $0.23-1.36$ & 0.69 & $0 \cdot 15$ & $0.32-1.45$ & 0.04 \\
\hline Galactose & $1 \cdot 70$ & 0.34 & $0 \cdot 78-2 \cdot 82$ & $1 \cdot 75$ & 0.32 & $0.98-3.02$ & 0.05 \\
\hline Glucose & $5 \cdot 70$ & 0.82 & $3 \cdot 37-9 \cdot 89$ & $5 \cdot 81$ & $1 \cdot 07$ & $3 \cdot 54-11 \cdot 81$ & 0.11 \\
\hline
\end{tabular}

* Differences were not significant.

$\dagger$ Anhydro sugar units $(\mathrm{g} / 24 \mathrm{~h})$.

$\ddagger$ Corrected for starch.

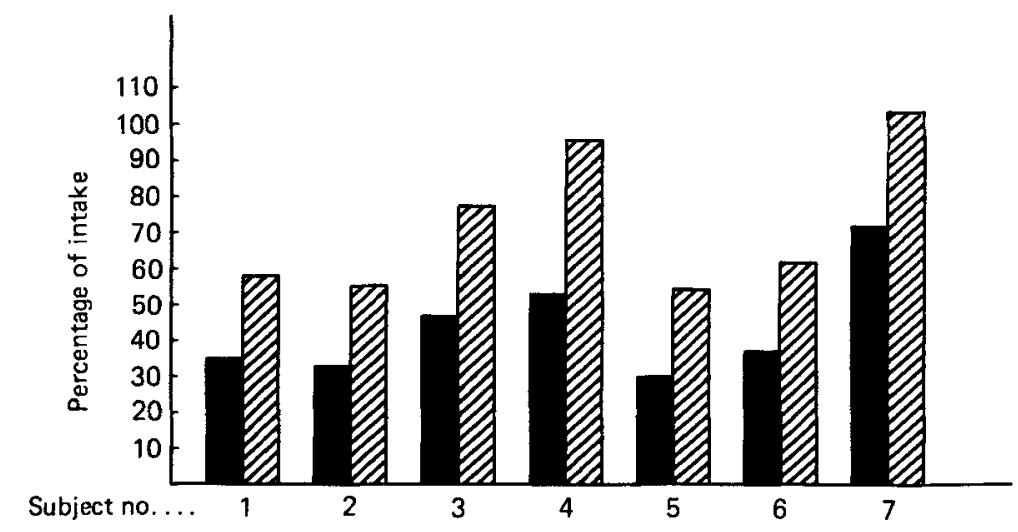

Fig. 1. Recovery of phytate in ileostomy contents of seven subjects studied during two periods on a constant low-fibre diet. In period A ( $\square$ ) the diet was supplemented with $54 \mathrm{~g} / \mathrm{d}$ of a bran-gluten-starch mixture and in period B $(\square)$ with the corresponding extruded product.

\section{DISCUSSION}

Although the daily ileal contents emptying in the colon in healthy subjects is three times higher than that in ileostomy subjects (Philips \& Giller, 1973), there appear to be no other differences as regards digestive or absorptive processes (Hill, 1976). The time taken for the head of a meal to reach the ileostomate's terminal ileum is identical to the mouth-to-caecum time of normal subjects (Holgate \& Read, 1983). Fermentation by ileal bacteria does not seem to be a confounding factor in healthy ileostomates as breath hydrogen (Holgate \& 
Read, 1983) and volatile fatty acids (Chapman et al. 1985) in ileal effluent did not rise after a carbohydrate meal. In agreement with Chapman et al. (1985) we believe that healthy ileostomates are suitable for quantifying absorption by simple intake-output studies.

Formation of amylose-lipid complexes, during extrusion cooking, which are resistant to amylase digestion in vitro has been reported in the literature (Mercier, 1980). However, such complexes are completely digested and absorbed in the rat intestine (Holm et al. 1983). The present study also supports the idea that the amylose-lipid complex formed during extrusion cooking using mild conditions has no effect on starch digestion or excretion of fat and fatty acids.

The almost-complete digestion of starch in the stomach and small intestine in both periods of the present study is in agreement with our previous studies on the digestion of rice in ileostomy subjects (Sandberg et al. 1981, 1982a), but is in contrast with other recent studies which claim that up to $20 \%$ of the starch in a meal may be passed undigested to the colon as measured by the aspiration technique (Stephen et al. 1983) or by breath $\mathrm{H}_{2}$ (Andersson et al. 1981). The discrepancy between our results and those of Stephen et al. (1983) may be due to the fact that in their study the sources of starch were not only rice but also bananas, potatoes and beans. Another possible explanation may be the difficulties in getting a representative sample of the intestinal contents when using the aspiration technique, or that intubation may affect intestinal transit and digestion.

No effect of extrusion cooking of the bran-gluten-starch mixture on the amount and composition of fibre components was found in the present study. This agrees with a collaborative study organized by Varo et al. (1983), in which the dietary fibre content of cooker-extruded wheat and whole-grain-wheat flour was compared with the raw materials. In the present study the digestibility of fibre components in the stomach and small intestine did not differ between the raw ingredients and extruded product. The fibre components seem to pass through the stomach and small intestine without digestion occurring, as we have shown earlier (Sandberg et al. 1981). The amount of polysaccharides derived from bacteria or endogenous material in ileostomy contents are included in the determination of fibre components and were supposed to be constant in the two periods when each patient served as his or her own control.

During the period of consumption of raw ingredients, a recovery of $44 \%$ of dietary phytate (mainly derived from wheat bran) was found, which corresponds well with our previous studies where $41 \%$ of the phytate in $16 \mathrm{~g} \mathrm{AACC}$ wheat bran was recovered in ileostomy contents (Sandberg et al. 1982 b). In both these studies, the microbial growth was minimized by the routine described previously and therefore the hydrolysis of phytate cannot be attributed to microbial phytase activity, but to hydrolysis by human phytase or alkaline phosphatase (EC 3.1.3.1). According to Bitar \& Reinhold (1972), intestinal phytase activity is found in the mucosa of the small intestine of the rat, chicken, calf and man.

The amount of phytate analysed as phytate-P was not changed, or only slightly reduced, after extrusion cooking of the bran-starch-gluten mixture. However, in spite of the mild extrusion conditions, the phytate in the extruded product was much-less digestible in the stomach and small intestine than the phytate in the raw ingredients. There are two possible explanations for the reduced digestibility. First, there may have been loss of phytase activity during extrusion cooking and, second, there may have been a qualitative change in what we analysed as phytate-P. The first alternative is, however, contradicted by the results from our earlier study where the phytate in AACC wheat bran was largely digested (Sandberg et al. $1982 b$ ) although the enzymes, including phytase, were deactivated during preparation. The second explanation is the more likely. Precipitation with $\mathrm{FeCl}_{3}$ for determination of phytate-P probably also measures both inositol hexaphosphate and inositols with four or 
five phosphate groups. Inositol with four or five phosphate groups might be formed during extrusion cooking and might not be digested by the intestinal enzymes of man. Other indigestible phytate-complexes may also be formed. This will be further studied by qualitative analysis of phytate in food and ileostomy contents using high-pressure liquid chromatography.

In conclusion, mild extrusion cooking of a fibre-rich cereal product does not lead to important negative effects on the availability of protein, fat or starch. The possibility cannot be excluded, however, that this might occur with food products in the market which are extruded under higher pressure and temperature. Even under mild conditions, a possible impairment of mineral absorption, mediated by the resistance of phytate to digestion in the human gut, must be considered. The effect of extrusion cooking on apparent mineral absorption in the seven subjects studied will be reported separately.

The authors wish to thank Ms Raija Ahderinne for excellent technical assistance, Ms Helena Göransson and Ms Ingrid Jönsson for excellent assistance at the metabolism unit and Dr Yngve Andersson and Dr Lena Jonsson of the Swedish Food Institute (SIK) for preparing the extruded product. This study was supported by the National Swedish Board for Technical Development (Project nos. 70-5225 and 70-5226).

\section{REFERENCES}

Andersson, I. H., Levin, A. S. \& Levitt, M. D. (1981). New England Journal of Medicine 304, 891-892.

Bitar, K. \& Reinhold, J. G. (1972). Biochimica et Biophysica Acta 268, 442-452.

Björck, I. (1984). Nutritional properties of wheat products processed by HTST extrusion cooking, PhD thesis. University of Lund.

Björck, I. \& Asp, N.-G. (1983). Journal of Food Engineering 2, 281--308.

Björck, I., Noguchi, A., Asp, N.-G., Cheftel, J.-C. \& Dahlqvist, A. (1983). Journal of Agricultural and Food Chemistry 31, 488-492.

Chapman, R. W., Sillery, J. K., Graham, M. M. \& Saunders, D. R. (1985). American Journal of Clinical Nutrition 41, $1244-1248$.

Ellis, R., Morris, E. R. \& Philpot, C. (1977). Analytical Biochemistry 77, 536-539.

Fiske, C. M. \& Subbarow, Y. (1925). Journal of Biological Chemistry 66, 375-400.

Hallberg, L. (1984). Paper presented at the Nordic Symposium on Dietary Fibre, 1-3 June 1983, Umeå, Sweden. Näringsforskning 28, Suppl. 20, 56-58.

Harper, J. M. \& Jansen, G. R. (1981). LEC Report no. 10, Fort Collins, Colorado: Colorado State University.

Hill, G. L. (1976). Ileostomy: Surgery, Physiology and Management, 1st ed., p. 65. New York and London: Grune \& Stratton.

Holgate, A. M. \& Read, N. W. (1983). Digestive Diseases and Sciences 28, 812-819.

Holm, J., Björck, I., Ostrowska, S., Eliasson, A. C., Asp, N.-G., Larsson, K. \& Lundqvist, I. (1983). Die Stärke 35, 294-297.

Linko, P., Colonna, P. \& Mercier, C. (1981). In Advances in Cereal Science and Technology, vol 4, pp. 145-235 [Y. Pomeranz, editor]. St Paul, Minnesota: American Association of Cereal Chemists Inc.

McCance, R. A. \& Widdowson, E. M. (1942a). Journal of Physiology 101, 44-85.

McCance, R. A. \& Widdowson, E. M (1942b). Journal of Physiology 101, 304-313.

Mercier, C. (1980). In Food Process Engineering, vol 1, Food Processing Systems, pp. 795-807 [P. Linko, Y. Mälkki, J. Olkku and J. Larinkari, editors]. London: Applied Science Publishers.

Nävert, B., Sandström, B. \& Cederblad, Å. (1985). British Journal of Nutrition 53, 47-53.

Philips, S. F. \& Giller, J. (1973). Journal of Laboratory and Clinical Medicine 81, 733-746.

Sandberg, A. S., Ahderinne, R., Andersson, H., Hallgren, B. \& Hultén, L. (1982a). Human Nutrition: Clinical Nutrition 37C, 171-183.

Sandberg, A.-S., Andersson, H., Hallgren, B., Hasselblad, K., Isaksson, B. \& Hultén, L. (1981). British Journal of Nutrition 45, 283-294.

Sandberg, A.-S., Hasselblad, C., Hasselblad, K. \& Hultén L. (1982b). British Journal of Nutrition 48, $185-191$.

Stephen, A. M., Haddad, A. C. \& Phillips, S. (1983). Gastroenterology 85, 589-595.

Swedish National Food Administration (1978). Food Composition Tables. Stockholm: Liber Tryck.

Theander, O. \& Åman, P. (1979). Swedish Journal of Agricultural Research 9, 97-106. 
Theander, O. \& Westerlund, E. (1986). Journal of Agricultural and Food Chemistry (In the Press).

Van de Kaamer, J. H. Ten Bookel Huinink, H. \& Weyers, H. A. (1949). Journal of Biological Chemistry 177, 347-355.

Varo, P., Laine, R. \& Koivistoinen, P. (1983). Journal of the Association of Official Analytical Chemists 66, $933-938$. Westerlund, E. \& Theander, O. (1984). Paper presented at the Nordic Symposium on Dietary Fibre, 1-3 June 1983, Umeå, Sweden. Näringsforskning 28, Suppl. 20, 39-41. 